\title{
SUPPLY AND DEMAND IN THE DEVELOPMENT OF PROFESSIONAL ETHICS
}

\author{
Hugh Breakey ${ }^{1}$
}

\begin{abstract}
How can we explain the development - or equally the non-development - of professional ethics norms in a particular case? And how can we enhance compliance with existing professional ethical norms? In this paper, I develop a supply/demand theory of professional ethics. That is, I consider the demand-forces and pull-factors that call for the construction, reform or continuance of a professional ethos. These demands may come from various stakeholders, including individual service-providers, the professional community, actual and prospective clients, and the general public collectively as interested third parties. The supply-side, on the other hand, constitutes the ethical materiel out of which norms emerge: these are the felt-motivations of individual professionals at the coalface of action that drive them to recognize, acknowledge and act upon a professional norm. This materiel includes traditions and stories, the conscious application of common-sense ethics, explicit endorsement of public moral codes, internal excellences within the activity, a discrete community capable of cultivating attractive role-identities, and so on. As well as considering such ethical-materiel, I canvas the institutional and cultural supports that facilitate the production of these motives.
\end{abstract}

Keywords: Professional ethics; professionalization; moral motivation; common morality; business ethics.

\section{INTRODUCTION AND ASSUMPTIONS}

This paper develops a supply and demand explanation of professional ethics. It describes the various pull-factors impelling various actors to demand the creation of a norm, and the myriad push-factors (including moral springs such as status, identity, role, narrative, tradition and excellence) that supply the elements out of which a norm, and the accompanying motivations to act upon it, can be fashioned.

\footnotetext{
1 This manuscript is the postprint version of: Breakey, H. 2016. Supply and demand in the development of professional ethics. Research in Ethical Issues in Organizations 15: 1-28. The final publication is available at Emerald Insight at https://www.emeraldinsight.com/doi/full/10.1108/S1529-209620160000015001
} 
What I aim to help explain, in particular, is why we do not see strong community-constructed codes arising in other sectors that may have similar sorts of demanders. Why don't we see professional collective codes of conduct arising for car mechanics, naturopaths and product salespersons? Is that the demanders in this case possess less urgent needs? Or is it that we lack the supply-side materiel, and the cultural and institutional facilitators of that materiel?

In focusing on explaining the emergence of strong professional ethical codes, this project differs from the myriad sociological explanations of how professional organizations and communities emerge. These inquiries share much in common, and I will draw on some sociological literature in what follows. In particular, many of the demand-side features will be similar, at least for those sociological theories that allow for a multiplicity of causal factors and - with Weber rather than Marx - emphasize individual agents' deliberate projects to construct a profession (Macdonald, 1999, pp. 1-7, 27-29). Yet the inquiries remain separate: it is possible to construct a powerful professional organization where the 'ethic' remains mere rhetorical gloss or slick public relations spiel. In contrast, I focus exclusively on the construction of genuine ethical norms.

Looking at professional ethics this way involves making a few major assumptions.

First, I assume that genuine recognizably ethical drives to act against one's narrow self-interest exist, and that enhancing these drives constitutes one important method of improving compliance with professional standards. Naturally, I do not suggest that ethical culture and mindset compromise the only mechanisms for improving compliance. Instead, they make up one part of a larger portfolio of mechanisms. We can see this, for example, in Charles Sampford's 'integrity systems' approach, where moral motives sit alongside legal instruments, economic incentives, governance mechanisms and more (1994). Similarly, moral norms constitute just one part of Justin O'Brien's CEDAR approach, where (E)thics takes its place amongst factors including Compliance, Deterrence, Accountability and Risk (0’Brien \& Dixon, 2013 - see similarly the three-level governance approach of Macaulay and Arjoon, 2013). Thus, while I focus here exclusively on improving the motivational push of professional norms, this must be understood as one part of a larger toolbox of potential levers of reform, including economic, political and governance mechanisms. Of course, attending to ethics can respond to the 'enemy outside' by fixing the 'enemy inside' (Macaulay \& Arjoon, 2013, p. 521).

My second assumption is that merely wanting a norm to exist (say for the collective benefit of one's group) does not wish that norm into existence - even if the community that wants the norm is the very community that would shoulder its obligations. A norm exists when individuals at the coalface, voluntarily and with little thought for who is watching, comply with the norm on the conviction that the norm warrants respect. ${ }^{1}$ Crucially, that a norm would be in a group's collective interest does not at all show that the norm exists and that it regulates each member of the group. As the well-known phenomenon of the 'tragedy of the commons' illustrates (Hardin, 1968), a group can unanimously 
recognize they would all be better off with a norm motivating a shared course of action, and at the same time bemoan that they do not possess such a norm. What this means is that as well as having demanders outside a service-providing-sector calling for the construction of a norm, we can equally well have demanders inside that sector who desire the norm and yet lament its non-existence. This is why in what follows, I will include professionals themselves as 'demanders' for the norm, and consider the supplyside question of normative motivation separately. Professionals themselves are not norm-suppliers (instead, they constitute a special case of demanders).

My third assumption is that merely because a norm is justified - even consciously accepted as justified by the agent in question - does not guarantee that agent's compliance. Plainly, working out the ultimate justification for, and articulation of, professional norms remains a matter of no small moral and philosophical significance. But my question here lies elsewhere. Here our interest concerns how to motivate widespread compliance with (and hence to establish the social reality of) a professional ethic. Compliance is not (only) a question of whether the norm can be morally and philosophically justified from an objective standpoint. The question of compliance amounts to a question of motivation. In any given case, for any given agent, that agent can have diverse motives to comply, myriad temptations to excuse herself, unhelpful habits or cognitive lapses that stymie compliance, or pressures to defect from the norm. As Heath (2008) stresses, in the context of business ethics, non-compliance typically derives less from a disagreement about values, but more from the availability and self-interested employment of excuses and rationalizations. Equally, an ultimate justification can sometimes seem far off and removed - perhaps because the 'norm-demanders' are not present, appreciative or vocal. Furthermore, a well-known and widely-accepted principle may, in some situations, impose especially onerous duties, and hence require greater motivational force than usual to secure the same level of compliance.

As a result of these several factors, having a single objective justification for a professional norm (though no doubt important) does not exhaust our interest in other supply-side ethical materiel that may bolster widespread respect for the norm, and drive compliance with its obligations even in the face of substantial temptations and pressures. Thus, while the following supply-factors draw on moral justifications for professional ethics, I focus on felt-motivation rather than objective justification. When I draw on a particular justificatory story for a professional norm, the question in each case is how far that particular justification taps into the emotions, relations, habits and thought-processes of the decision-making professional. How does the situation and context of the professional conspire to make a particular justification vivid and salient, and so capable of driving compliance?

As a final assumption, I limit the following analysis to contemporary liberal democracies. In structurally different political, economic and social conditions, a very different demand-supply formula may appear. 


\section{THE PROFESSIONAL ETHIC}

What is the professional ethic that is being demanded and supplied in each case? Naturally, and importantly, differences can arise between the content that is demanded even by different constituents of a single professional organization - and even stronger differences in desired content can emerge when we consider the demands of clients, individual third-party stakeholders, and the community at large. And even if there was univocal agreement by all these disparate demanders, the supply-side materiel might drive the performance of a norm with quite different content again.

Yet, in each case, there remains a single designated object that the contest revolves around: that is, the professional ethic that aims to regulate the conduct of the professional in her professional activities.

Moreover, I will take it that the ethic in question, to count as a professional ethic on any ordinary construal, will contain the following staple features.

First, the professional ethic is collectively created by the profession itself, and is articulated in the profession's self-understanding and usually delineated in concrete codes of conduct. That is, the professional community or organization constitutes the final arbiter and decision-maker on the substance of the ethic, though of course that collective may well select that content in response to pressures or opportunities created by community or client expectations. The profession also makes some effort at policing compliance with the ethic, and possesses an array of sanctions it can draw upon in cases of serious breaches.

Second, in terms of substance, I take it that the professional ethic will always require competent standards of service, backed up by (at least quasi-)fiduciary duties to clients, namely, to act in their interest, heed their choices, and respect their confidentiality. ${ }^{2}$ The professional ethic, in other words, centres on the service to the client, and scrupulously avoids tainting that service with any ulterior motives. Despite this client-centred focus, there will usually be some obligations to the society more generally (or to its institutions, such as lawyers' duties to 'the court'). There may also be certain duties owed to the profession itself, and largely for its collective benefit.

\section{DEMANDERS}

'Demanders' include all stakeholders who call for the construction, continuance or reform of the professional ethic. We can characterize them as saying, "We want all those providing this service to be bound by an ethic because..." Demanders include those calling for a profession to be created in a service-sector where no profession currently exists. (This is why I will speak throughout of 'serviceproviders' rather than of professionals, unless the context makes it clear that a profession has already been created.) 
Demanders fall into three main groups: individual service-providers; clients and prospective clients; and the society at large.

\section{Individual service-providers}

Individual service-providers can benefit from professional norms on several different bases, and so desire the norm's construction, reform, continuance and enforcement. Cultivating the norm in these ways requires coming together as a collective, so although these are reasons that will appeal to individual service-providers, they impel action as a collective.

One of the major benefits to individual service-providers from a professional norm's existence is the creation of a climate of trust between prospective clients and service-providers. ${ }^{3}$ Even setting aside the desirable social status that this trust nourishes, such trust carries an array of material and other benefits. It enhances widespread use of the service, allowing prospective clients to trust professionals implicitly and employ their services without hesitation. The trust also helps to gain or sustain the service-sector's social and legal license to operate. This is especially relevant if any specific legal exceptions are required to facilitate the smooth running of the professional service, such as confidentiality duties allowing professionals to avoid legal reporting duties (McGraw, 2004) and special exceptions required by the medical profession in dealing with drugs and human bodies (Rhodes, 2001). Trust in the specific servicesector also prevents potential clients attempting to fulfil their needs by taking their business to a cognate service-provider (such as going to an accountant or an estate-planner instead of a financial planner). In this way, the professional ethic can favorably impact upon inter-sector competition. ${ }^{4}$ Generic trust in the profession also removes the need for an individual to establish their own trusted brand, which helps restrain costly intra-sectoral competition (constraints on individual advertising help here too (McGraw, 2004)).

The creation of a professional ethic requires competency standards, which usually mandate various educational or knowledge-based standards (such as entrance exams) that professionals must meet. For the self-interested professional, these standards tend to create the happy result of barriers against other practitioner's easy entry into the market, creating a quasi-monopoly that inflates service-costs. (For this reason, presumably, many professions make the educational requirements greater than ordinary competence would require (McGraw, 2004)).

Additionally, the self-regulation offered by a professional organization may be viewed by the professional as preferable to regulation by the government. Laws created by legislators and regulators remote from professional realities and priorities can prove clumsy and ham-fisted.

So far, these demanders have been quite self-interested. The creation of the professional ethic, and its articulation and enforcement through the professional community, promise substantial financial and legal benefits. But the professional committed to high standards of service and moral rigor also benefits 
from the development of a profession-wide ethic. In particular, possessing a standardized ethic prevents each individual professional being faced with market or occupational pressures to lower their standards (as Davis (1991) relates in his exploration of the pressures placed on engineers' ethics that ultimately led to the Challenger space-shuttle disaster).

Summing up, for reasons based on improved social status, legal exemptions, expected financial rewards and improved support for individual's own moral standards, individual professionals constitute key demanders for the development of a professional ethic. To rehearse a point made earlier, however, the presence of this demand does not itself magically create the desired professional norm. The ethic itself must be constructed out of available materiel, and supported by the requisite institutions.

\section{Individual clients and prospective clients}

Clients and prospective clients help drive the development of professional ethics, for it is they who are usually the norm's most direct beneficiaries.

Why do clients demand professional norms? Or, more specifically, why do clients of certain types of services (such as medicine and law) demand norms protecting them in ways that normal purchasers of market services and products do not? After all, most purchasers of services in the market could be expected to desire increased care and attention for their wishes, confidentiality and decision-making autonomy. Why is the demand for the norm different for the particular services we tend to recognize as professions?

As the literature shows, clients of these services suffer several distinct types of special vulnerabilities, which together give greater urgency to their demands for fiduciary treatment.

First, many such services provide for very basic, and even inescapable, human needs in modern society. Medical needs (including doctors, nurses and pharmacists) and legal needs furnish obvious examples. Sometimes the need for such services can be urgent indeed - so urgent the client cannot select amongst service-providers. The emergency room presents a striking example here, but many serious illnesses require diligence and high standards from myriad service-providers the patient may never meet (such as pathologists). For other services, even if they do not cater to people's fundamental or urgent needs, such services constitute unavoidable parts of other important endeavors: endeavors required at the societal level. Engineers, architects and accountants provide examples here. These services are at least somewhat inelastic $;{ }^{5}$ if service-provision in these sectors is sub-quality, a prospective client cannot simply engage a different sector to answer to her needs. ${ }^{6}$

Second, prospective clients suffer from knowledge (epistemological) vulnerabilities. Clients lack information about the specific area of expertise wielded by the service-provider. Moreover, because that expertize often involves years of study and the capacity to judge subtly amid conflicting signals and 
pressures, ordinary clients are ill-equipped to become informed. Worse still, the level of their knowledge deficit rises to such an extent that they are not only unable to prospectively judge high-quality service, they usually cannot retrospectively do so. That is, having been given legal, medical, engineering or pharmacological advice, clients rarely find themselves in a position to accurately judge the quality of that advice. (Compare this to the services offered by a car mechanic. Even if we know little about how cars work, or what was wrong with our car in this instance, we can usually at least tell if the mechanic has succeeded in fixing the car.) Even if the advice fails to achieve its desired effect, the client may not know whether this misfortune resulted from poor advice or other factors. This means that poor service cannot educate any given client; as well as not being capable of self-education to learn prospectively about service quality, the client cannot even learn for themselves (except fitfully, unreliably and occasionally) about the quality of the service they have received. In turn, this means that normal reasons we have for trusting to people's personal responsibility for informed decision-making and self-education (Attas, 1999; Breakey, 2012) cannot apply in this case. Furthermore, the inability to make accurate retrospective judgements means that ordinary market pressures fail to act in productive ways. That is, market pressures that might otherwise respond to poor service provision when previous consumers vote with their wallets, and by this means send signals to other market-players, will not function well in this context. As Michael Davis (1988, p. 353) puts it, the market can prove deaf to the "invisible quality" we demand of professionals like lawyers and doctors.

Third, the service itself involves the client making herself vulnerable. Certain services require of the client that she exposes, warts and all, her personal history, future plans and even physical body to the service-provider. This process of exposure, and the resulting knowledge and documents in the hands of the professional, create new vulnerabilities.

A fourth vulnerability emerges because if the provided service is very poor, the result may be catastrophic for the client. Even if clients were able to accurately judge the quality of service after they have put the advice into practice, the potentially exorbitant costs of faulty (accounting, legal, engineering, medical - one might add financial) advice render trial-and-error 'shopping around' for a high-quality service-provider fraught with peril.

These four factors combine to create a perfect storm of vulnerability. As a result, clients and prospective clients demand high-quality services with host of a quasi-fiduciary obligations on the part of the serviceprovider. ${ }^{7}$ Moreover, the clients require these as standard across the service-sector, because they cannot (even with appropriate and judicious self-education) select high-quality services for themselves. They thus demand the ethos because they need professionals, as a rule, to be trustworthy in confidence, competence and intention.

While important, these vulnerabilities do not ipso facto create the reality of a professional ethic (as Rhodes (2001) can sometimes seem to imply in the context of professional medical ethics). Service- 
providers can simply exploit these vulnerabilities, secure in the knowledge that clients will in any case have to engage with them. After all, in other market sectors, profiting because of a buyer's need or ignorance is often seen as morally excusable, if not outright good business.

\section{Wider community/third parties}

Clients are not the only non-professionals who possess a stake in the services offered by professionals. ${ }^{8}$ Specific third-parties, and sometimes the community at large, can suffer from professional malfeasance. Third parties can suffer from discrete ethical failures, such as when a negligently-engineered bridge collapses on top of them - or the spacecraft they are piloting explodes (Davis, 1991). These victims are not the paying clients of the professional - yet they suffer directly from failures of ethics and competence. Equally, the entire society can suffer from large-scale and widespread ethical failures. The clear example here is the Global Financial Crisis, created in no small part by failures in ethics on the part of accountants, bankers and financial advisers (Curtis, 2008). The Global Financial Crisis savaged investor trust, slowed economies and drove up unemployment, creating countless victims who bore no relation to the initial ethical failures.

Complicatedly though, third-parties can also be threatened by professionals' faithful allegiance to their professional ethic. Professional codes primarily benefit the client and/or the profession itself - and these priorities can impact on those in the wider community. Such victims (and those concerned for them) still count as 'demanders', because they rarely wish to purge the entire professional ethic. Rather, they constitute reformers, who want the ethic to remain, but to be more responsive to third parties' needs. Common examples of this type of third-party demander include those persons at risk because of legal or medical confidentiality duties that prevent alarms being raised, or prevent information (such as their legal innocence) being brought to light.

Another demander/reformer group includes those prospective clients who would benefit from increased advertising and knowledge of fee structures, as many professional norms constrain various forms of direct advertising. In such cases, the community's demands can be represented through courts, which may strike down as illegal these barriers to the ordinary flow of market information.

How do each of these types of demanders make their demands felt?

Not all demanders are equal when it comes to forcing and facilitating the development of professional ethical norms. Each wields different tools, with varying effectiveness.

Clients and prospective clients can vote with their feet and with their wallets, especially in cases where a visible and reliable portion of the service-sector display appropriate standards. In such a situation, if the overwhelming majority of clients flood to service-providers able to demonstrate high-quality standards (such as through membership in a bona fide professional organization), then market pressures 
work to drive the ethic and the institutions that support it. Clients can also try to hold out for improved contracts and established expectations between professionals and clients. Sometimes, they will be able to pursue serious breaches of ethics through civil (or even criminal) law.

Third-parties and the general community enjoy less direct control over service-providers. This demander-group can determine the service-sector's social status - retracting its standing in the face of breaches of trust (as has occurred, to some extent at least, with bankers and accountants in the face of the Global Financial Crisis). The community also wields another tool; their capacity to vote for changes in legislation and regulation. Each of these levers amount to clumsy fixes for breaches in standards and ethics, but they can change the structural environment in ways conducive to future improvements. For instance, a legislative change in who can use the term 'financial adviser' can empower professional organizations by requiring membership in return for use of the sought-after term. This can in turn elicit larger improvements in standards.

Through the mechanism of government, the community can also offer a 'carrot' approach to improving supply. For example, in Australia, the Professional Standards Councils provides an example of a government institution designed to improve and invigorate professional organizations. In return for demonstrating professional standards, and education and enforcement mechanisms, organizationmembers can enjoy limited liabilities, as well as official state recognition of their professional status. ${ }^{9}$

Service-providers themselves possess different means at their disposal - most obviously by deliberately cultivating any of the following supply-side factors that can improve their own compliance. They can also play a crucial role in progressing their fellow service-providers' ethical standards, such as by esteeming colleagues who fulfil their professional role-identity, or who demonstrate excellence in their standards of service. Service-providers can also facilitate ethical development by joining and supporting professional organizations with high standards - and being on guard for those organizations succumbing to the ever-present temptation to focus more on increasing member benefits than on moral standardsetting.

\section{SUPPLY FACTORS}

Unlike demanders, supply-factors are not persons or groups, but sets of motivations that drive intrinsic respect for the norm and ensure compliance occurs in the field, in the face of the inevitable temptations and pressures to defect. Supply factors provide a completion to the sentence: "As an individual serviceprovider, I obey this norm because I think/feel that..."

As well as listing the major supply factors driving compliance with a professional norm, this section also notes, where relevant, any institutional or cultural prerequisites (or facilitators) for a given supplyfactor. For instance, a society that provides little social status or material reward for a professional group 
can expect no professional compliance on the basis of a fair quid pro quo with the local community, as the social benefits that trigger such a norm do not exist. This means that other supply-factors must be brought to bear to secure widespread compliance in such an environment (a subject Tetsuji Iseda (2008) explores in the context of engineering in Japan).

In what follows, I gesture towards the general institutional facilitators of the norm in question; but a finer-grained analysis (honing in on a specific service-sector in a specific country) would reveal more granular institutional requirements. For example, while many of the following supply-factors require a vibrant and well-resourced professional organization, this requirement equivocates between a professional organization that holds a legal monopoly on service-delivery, an organization that is purely voluntary and holds no regulatory recognition, and the many cases in between — such as where ordinary practice does not require professional membership, but membership tends to be recognized with greater remuneration and responsibility (McGraw, 2004). In some cases, a voluntary organization might be enough to develop the supply-factor, but other contexts will require the reliability and standardization of an organization possessing legal clout.

\section{A byword: self-interest as norm motivation}

The above definition for a professional norm requires that self-interest cannot itself count as a supplyfactor, as supply requires some type of intrinsic respect for the norm per se (and not merely complying in those instances where compliance will redound to the agent's personal advantage). However, selfinterest still bears mention in this context. As Bernard Williams (2002, p. 94) observed in his work on the norm of truthfulness: "it is vital that on many occasions there are obvious reasons of self- or groupinterest... constant injections of reasons for action which are obviously self-interested help to warm the tubes of the normative circulatory system." In this spirit of "warming the tubes," it is worth enumerating the self-interested reasons that professionals may have for obeying the established norm.

First, in cases where there are social, legal or financial benefits to the members arising from the existence of the professional norm, each professional contributes to the continuance of those benefits from her current compliance. The actual benefit she herself derives from her own actions is mediated and indirect, to be sure, but nonetheless furnishes one reason to comply. This motive usually requires institutional facilitation by an established professional organization that receives manifest social, legal or financial benefits from the community and clients.

Second, while professionals can rely somewhat on their branding as a member of a professional community in good standing, personal branding still matters. Professionals providing high standards of quality service can create a proven track record, and enjoy at least word-of-mouth advertising and referral on its basis. 
Finally, professionals have a self-interested reason to avoid legal, social, financial or employment-based sanctions for non-compliance. This motive requires an effective self-regulating professional organization, or at least pro-active regulatory and legal governance, capable of assigning blame and sanction for wrong-doing.

Turning from self-interested motives for compliance to genuine ethical support-factors, I list six distinct types of motives: 'desirable role-identity', 'excellence', 'common morality', 'covenants', 'constructed virtues' and 'true glory'.

\section{Desirable role-identity}

Distinct role-identities can be inspiring and admirable, both from the outside (as ordinary communitymembers appraise the professional) and from the inside (the felt experience of a practitioner living up to her role). The admiration accruing to such identities provides a reason to live up to them. In an insight going back to Aristotle (350BC/2002) and playing a central role in the ethics of David Hume (1739/1969), people like to take pride in themselves by becoming people they admire. Provided that those role-identities include compliance with the key professional norms and virtues - which is usually one part of what makes the role-identities so admirable in the first place - this self-admiration can constitute a major factor in propelling compliance.

The desirability of certain role-identities can be almost irremovable from the particular service provided. For example, the very nature of the medical professional involves healing, which is at once an exercise of power and inherently beneficial to those receiving it. One might doubt whether any society throughout history failed to revere its healers in some way.

Often though, role-identities need to be brought to life in various ways. They may be vivified in narratives and myths - such as stories celebrating lawyers defending the wrongly-accused innocent. Traditions, too, may burnish the role-identity with the luster of ancient lineage; contemporary medical professionals can draw a line in their current virtues all the way back to the Hippocratic Oath, and feel themselves following in the footsteps of a steeped tradition. Professional roles can partake of previous traditions infused with attractive notions of honor, such as gentility and noblesse oblige (Macdonald, 1999, p. 10). Alternatively, the allures of the role might be hammered home by famous leaders or historical personalities whose feats become front-page news - such as investigative journalists who uncovered major political scandals. When studies of professional ethics and education touch upon the high ideals of aspirants to the profession (Kelly, 1998; Luban, 2003), it will often be such stories that drive the aspirant's wish to belong.

While important, it may not be easy to construct these supply-side factors. All these facilitators of supply-side admiration for role-identities require an existing canon of historical or fictional figures and steeped traditions. 
Another reason for wanting to live up to a role-identity emerges when one feels invested in the identity. Whether or not the general community admires the role-identity, the professional may nevertheless identify with it (Hall, 1982; Newton, 1982). The identity forms part of their self-concept, and they aim to live up to it simply because it reflects how they see themselves. A key here lies in the creation of a sense of ownership over the distinctive role-identity. The fact that the profession itself develops the professional ethic, and that its members can see the ethic as reflecting their own thinking, work, practice and commitments, enhances this sense of personal and collective investment. So too, substantial barriers to entry into the community (through educational and other requirements) can nourish this sense of collective ownership over the role-identity and its moral components.

The sense of ownership and identification thus requires the existence of a professional organization constructing the code of conduct, especially if the organization encourages widespread debate and participation amongst the professional community whenever the code is constructed, reformed or considered. Similarly, institutional barriers preventing easy entry to the community encourage a sense of distinctive identity.

Other factors may help. Many codes have restrictions on advertising - constraints that can cultivate the profession's dignity, raising it above the rough-and-tumble of ordinary market players, and augmenting its attractions and aura of honor.

\section{Excellence}

As Alasdair MacIntyre (1981) argued in After Virtue, practices can create their own standards of excellence, and traditions can help hone and encourage those standards. In turn, these standards give rise to virtues, understood as emotional and intellectual traits that empower excellence in the practice. Many people find the pursuit and achievement of excellence intrinsically rewarding; MacIntyre (1981, pp. 175-177) refers to these emotional rewards, and the desirable way of life accompanying them, as the 'internal goods' of a practice. As such, excellence, and pride in one's excellence, provides a distinct drive towards professional virtue (see Iseda, 2008).

Of course, the excellences of a given practice may not turn out to result in recognizable moral virtues (though MacIntyre (1981) argues that some staple virtues will emerge across all practices). The excellence of salesmanship, for example, might revolve around rhetorical manipulation, by hook or by crook, in teasing open a buyer's purse-strings. But for many professions, ethical constraints draw the borders within which the pursuit of excellence may take place. The doctor who excels at healing, and the lawyer who expertly wields the law in defense of her client, are required to perform excellently within the bounds set by their professional moral obligations. Breach of the norms amounts to cheating, and the cheat fails to achieve - the cheat no longer even attempts to achieve - the activity's excellence. 
As such, while the pursuit of excellence may not explicitly focus on other-regarding ethical imperatives, it can nevertheless provide a strong drive to comply with ethical norms.

This supply-factor, often simply characterized as 'doing the job well', can be facilitated by various institutional means, including practices of apprenticeship and education (MacIntyre \& Dunne, 2002), the significance of mentors and noted figures of excellence, and of community communication of standards and recognition of exemplars. Generally speaking, the more networked and closely-knit the community, the more we might expect commonly-held standards of competence and excellence to emerge and to attain strong motivational force. Team-environments will be a paradigm case of such close-knit groups.

\section{Common morality}

Several notable theories of professional ethics (e.g., Beauchamp \& Childress, 2009) see professional ethics as the direct application of common moral principles onto the fact-situations presented by the professional's expertise and the client's various vulnerabilities.

Along with several other authors on professional ethics (Freedman, 1978; Rhodes, 2001; Tapper \& Millett, 2014; Veatch, 1979), I find this avenue leaves several major features of professional ethics unexplained; in particular, the nature of its substantial ences from ordinary business ethics. ${ }^{10}$ Even so, I can hardly deny that, for the greater part, professional ethics parallels, specifies or elaborates on common-sense moral principles, such as beneficence, honesty and respect for others' autonomy. To the extent, then, that the professional harbors a respectable moral character, their ordinary commitments to these everyday moral principles will serve as a supply-side driver to their professional ethical conduct.

Even though this supply-factor rests upon moral inclinations that are (ex hypothesi) widespread across the population, institutional facilitation can still be helpful. Codes of conduct delineated and publicized by professional organizations draw attention to how ordinary moral principles apply in complex situations, and highlight morally relevant issues that might otherwise lie unnoticed. Community interaction that creates avenues for peer advice and mentoring can similarly facilitate the activation of ordinary moral fillips. Even academic studies and official reports on ethical issues can help by clarifying how ordinary morality applies to professional contexts.

As well, we can think of the teaching of professional activity constrained by ethical norms, as developing 'scripts' (habitual and set cognitive processes for handling complex problems) that themselves fit within moral bounds. Because scripts developed without conscious ethical reflection can lay the groundwork for moral catastrophes (Gioia, 1992), the development of morally-constrained scripts can prove a vital mechanism for rendering complex work morally justifiable as well as intellectually manageable. 
A commitment to ordinary moral principles can also drive the need for standardized codes consistent across the profession. If moral standards cannot secure consistency among professionals - either for reasons of some members' immorality, genuine and legitimate moral diversity, or the latitude allowed by 'imperfect' duties (Igneski, 2006) - then a professional's high moral standards can prove an impediment to their employment prospects. As noted earlier, a professional organization enforcing standardized codes of conduct can be a necessary institutional requisite empowering individual professionals to resist race-to-the-bottom market or occupational pressures to lower their standards (Davis, 1991).

For all these reasons, even when professional obligations rest upon the relatively secure foundations of ordinary morality, institutional commitments to specific obligations can still enhance awareness and compliance.

\section{Covenants, fairness and tacit contracts}

'Common morality' approaches to professional ethics apply ordinary moral principles directly to the fact-situations emerging in professional activities. By saying it applies 'directly', I mean this application is not mediated through other contingent acts and circumstances, such as the existence of contracts or conventions. (Tapper and Millett (2014) stress this important difference.)

A further approach takes key principles of common morality - such as good faith, trustworthiness, respect for fair quid pro quos, and principles of fair contribution to collective goods - and then applies them to the existence of various social arrangements, conventions and expectations that arise in professional activities. On this footing, the ultimate justification for the professional ethic lies in common morality - but the existence of these mediated social and institutional structures shapes the ethic's substance, and triggers the motive to comply.

Three supply-side factors warrant note under this contractual-fairness banner (Veatch, 1979).

The first supply-side factor emerges as a sense of fairness or loyalty towards one's professional peers. This arises when the profession gains in some clear way from the existence of the professional norm. The most obvious benefits will take the form of high social status, increased financial remuneration, and/or legal exceptions for professionals engaged in their work activities. The institutional requisite here is a functioning professional community that secures social, legal or economic benefits for its members (Iseda, 2008). But even without such tangible benefits, the collective profession may enjoy increased trust from its clients and prospective clients. Over time, individual professionals' compliance to the ethic builds a climate of trust that all future professionals inherit. As Rhodes (2001, p.496) observes in the medical context, patients implicitly trust their doctors, "because a history of doctors (for the most part) acting for their patients' good has made medicine trustworthy. Physicians today are the heirs of trust..." For this reason, a professional who betrays that trust betrays the community of professionals. The 
defecting professional takes advantage of the benefits created by others in her group without similarly contributing to the collective good - and indeed undermines that good by risking the malfeasance coming to light, and potentially eroding that trust. Eschewing such unfair exploitation, the professional who adheres to the moral standard does the fair thing by their fellow professionals, who similarly constrain their self-interest in pursuit of the wider collective goal. As Davis (1988, p. 347) describes this motive: the principle of fairness demands, "each person voluntarily receiving the benefits of a morally permissible practice to do her prescribed part of maintaining the practice." The practice must be real, of course; if few other professionals actually performed their role, then the principle would not create collective benefits, and so not compel compliance based on group loyalty.

A second supply-side motive draws on the drive towards reciprocating the benefits the larger community bestows upon the profession and its members. ${ }^{11}$ A professional might feel obliged to reciprocate towards the community by performing special obligations either, (a) because she feels that an implicit contract has been constructed between her profession and the society for special privileges, and she wishes to respect the substance of that tacit contract, or (b) because she feels that the tacit bargain struck between community and profession represents a fair exchange, and as the beneficiary of the community's privileges, she thinks she should uphold her end of the quid pro quo. (These two ethical drives interweave, but they can be teased apart. The first looks to whether a tacit contract can be surmised to have taken place. As an ethical driver, this motivation presumably will be stronger in those professions, such as law and medicine, where an explicit oath takes place. The second motive attends to the fairness of the current arrangement in terms of relative costs and benefits, irrespective of whether a tacit contract could be imputed.) These two ethical drives require the existence of genuine benefits for the profession (social status, legal exceptions, or improved remuneration), the visibility of these payoffs to ordinary professionals in their day-to-day work, and the implicit understanding that these rewards follow from the profession shouldering special obligations.

The third supply-side motive emerges through a professional's respect for the implicit contract (or for the spirit of explicit contracts) she undertakes with individual clients. Ordinary morality, we might say, requires not only adhering to the letter of one's explicit promises and undertakings, but a more demanding requirement of trustworthiness, which includes living up to the spirit of any agreements or arrangements, and not allowing others to labour under a misconception of one's character or intensions. This requirement acknowledges that a person deserves another's trust only if she has their interests at heart and cares about what happens to them. This broad virtue of trustworthiness can itself be one component of the moral virtue of 'integrity' (Breakey, 2016; Graham, 2001, pp. 246-247) - a virtue specifically earmarked by Sharon Dolovich (2010) in her description of the character required to live up to a lawyer's professional responsibilities. These virtues of trustworthiness and integrity then attach to the agreement forged with the client, or the client's expectations about the service. (Alternatively, if the client's expectations turn out to be unrealistic or misplaced, then the trustworthy professional must be 
clear about the substance of the service she intends to provide - she cannot allow the interaction to proceed under a misconception.)

This motive does not require iron-clad, black-letter contracts, as it presses the virtue-holder to live up to the spirit of reasonable agreements. Even so, such motives can still benefit from social and institutional facilitators, such as clear, established and reasonable expectations of service held by clients, and promulgated by the professional body. Clear statements by the professional about her obligations, both as general commitments and towards individual clients, can help trigger her sense of honesty and integrity, and attach them to her professional ethic.

Summing up, trustworthiness, integrity and a sense of fairness can drive respect for covenants, quid pro quos and tacit contracts, providing important supply-side materiel for a professional ethic.

\section{Constructed virtues}

If professional ethics require special obligations, reflects Rosamond Rhodes (2006) in the context of medical ethics and Sharon Dolovich (2010) in the context of legal ethics, then wouldn't it require special virtues in professionals? Virtues can be defined here as enduring character traits governing emotional and cognitive responses to situations, that drive the responder to behave in appropriate and productive ways (see Hursthouse, 1999). For example, the virtuous agent feels the appropriate amount of fear (or anger, sadness, happiness) at the right times, in the right way and directed towards the right objects. 'Right' in all these cases refers to a larger standard, such as actions, relationships and work capable of consolidating into a full and complete (excellent) human life, or of psychological health more broadly (Macaulay \& Arjoon, 2013, p. 514).

This way of thinking about ethics dates back to Aristotle $(350 \mathrm{BC} / 2002)$ - and so does the hypothesis for how such character traits are acquired: namely, through repetition and habit, and immersion in a culture teaching and exemplifying the appropriate human excellences. Teaching the explicit rationale for the virtues helps, of course, but cannot supplant the need for emotional and cognitive habit-forming over an extended period of time. An example would be medical personnel working in a team for a lengthy period, where professional aspirants can witness, emulate and practice the ways that experienced professionals handle challenges. At this early stage, the newcomer's conscious motive for acquiring these virtues may be merely to fit into the team and function within it (Rhodes \& Smith, 2006). But after habit and cultural immersion have done their work, the professional medical practitioner has inculcated a new emotional and cognitive perspective with which to approach their work. True, the process might, in some cases, create work habits that are less than conducive to professional virtues (Kelly, 1998). But often, the practitioner will find themselves cultivating emotional responses that tend to elicit morally proper actions in future professional work situations (Rhodes \& Smith, 2006). They will have learned 
to 'think like' a doctor, engineer or lawyer - and part of that 'thinking like' will guide their moral deliberation and action in constructive ways (Davis, 1991).

These supply-factor's institutional facilitators have less to do with professional organizations and codes of conduct, and more to do with lived practices and work-experience, on-the-job training, internships and apprenticeships. Teamwork, mentoring and leadership can all be key drivers in the development of professional character.

\section{True glory}

Ethicists tend not to rank the pursuit of social approval and admiration, on its own, as a proper moral driver. They have strong reasons for not crediting such a motive; not all good acts will enjoy social approval, and not all approval-eliciting acts will be good, meaning that the naked pursuit of status will only contingently track actual good behaviour (and will, in any event, be done for the wrong reasons). Often, we conclude from this that only duty for its own sake - irrespective of social acclaim - constitutes the proper motive for moral action. But as Adam Smith (2006) observed, a middle position lies between these two poles. A person can be driven to receive social admiration for personal virtue, but only on condition that they actually possess such virtue. This motive of 'true glory' (as Smith termed it) finds no happiness in undeserved admiration, but revels in social approbation when based in fact.

Individual professionals can receive social admiration for their own work, and commonly enjoy a general social status deriving from respect for the profession generally. A professional who yearns after true glory will enjoy basking in this status - but only to the extent that she herself, and the profession more generally, actually warrants it. This approbation then serves as another supply-factor motivating the professional to high standards, and driving her to encourage her fellow professionals to the same heights. The cultural requisite for activating true glory is the existence of social respect, trust and status for the profession (Iseda, 2008), or at least for individual professionals who are known to perform well. Peer respect within the professional group itself may prove even more motivating.

\section{SUPPLY AND DEMAND INTERACTION}

Supply-side ethical materiel interacts with demander's needs in a variety of ways. This section sketches some of the standard and not-so-standard relationships between the two.

\section{Supply-side factors may not match demanders' wants}

We can perhaps all-too-easily conceive of a situation where supply does not meet with demand, in the sense of clients and communities calling for improved norms and better compliance, and a service-sector 
deaf to their entreaties - or a sector continually rebuffing the community with syrupy rhetoric about change and reform, without undertaking any meaningful action (the contemporary banking sector may furnish an apt example here - see 0'Brien \& Dixon, 2013, p. 964). After all, service-providers might reap a considerable profit by engaging in practices that a professional ethic would prohibit.

Supply can fail to match demand in other ways. In particular, the profession might enjoy strong supplyside drivers, but this ethical materiel might not match up to the specific content demanded by the community. Supply factors possess their own internal laws and constraints; it is not simply that any of the above supply factors can be shaped to motivate compliance with any given other-regarding ethical obligation. ${ }^{12}$ For example, the pursuit of excellence or a desirable role-identity might clash with a community's wishes, such as if the profession holds that its 'dignity' proscribes direct advertising, while the public demands the greater information and competition that advertising can generate (McGraw, 2004). Alternatively, the ethic might rely primarily on the direct application of common morality - but in a case where the community demands obligations in excess of everyday moral burdens, then these will go beyond what the supply-side factor can supply. Professionals might find that their everyday moral character fails to motivate these additional burdens.

A different situation can arise where an ethic emerges without major input from demanders: where supply exists without demand. The internal goods of an activity, a desirable role-identity, and constructed virtues can all arise through the natural collaborations of a close-knit community of peers; communities can spontaneously discuss and construct norms for their practices (Hall, 1982; Newton, 1982). External demand for the services rendered by this ethical community may ensure the profession and its ethic continue to flourish, but the ethic was not itself driven by, nor created in response to, such demanders.

\section{Supply can create demand}

While stressing the distinction between the two, and noting that we can have demanders without supply, and supply-factors present without these resulting from demanders, supply-factors can form a part of demanders' reasoning. Potentially, a service-provider envisaging a future profession might, reflecting upon the internal goods and felt-pleasures of each of the supply-side factors noted above, come to demand the creation of the professional ethic. The desire for social status presents a clear example of this. A service-provider might wish she was part of a sector that enjoyed social respect (and true glory), and therefore demand the development of a professional organization with high standards. In this way, the goods furnished by supply-side motives can form part of the portfolio of reasons some professionals might become demanders. 


\section{The dangers of in-group ethical constructions}

Some of the supply-factors noted above can be constructed entirely 'in house' - that is, purely by the service-sector and through its own activities and deliberations. The service-sector might allow scant participation or even observation by third-parties and the general community in constructing these ethical supports. Such internally constructed supply-factors can include excellence, virtue-construction, and desirable role-identity.

Some theorists (McGraw, 2004; Veatch, 1979) harbor suspicions about the moral legitimacy of these internally-constructed professional norms, at least when those constructs impact upon non-members. Certainly, it is true that, detached from client or community input, such norms may be more focused on ensuring and improving member benefits (even if just the internal goods of the activity), rather than on fiduciary duties to clients or wider duties to the community. Even if such norms do attend to the public interest, it may be the public interest as paternalistically interpreted and articulated by the profession (Veatch, 1979).

Yet, such in-house ethical supports should not be dismissed too quickly. Internally-constructed professional norms can be powerful motivators for action by providing ownership and a distinctive roleidentity. The professional can think of such norms as powerful expressions of her identity, and feel a strong identification with and ownership of them for this reason. As such, these norms may well be worth encouraging, so long as the good they motivate outweighs the bad they countenance. Freedman (1978, p. 14) suggests this line of argument when he pictures professional doctors as "zealots for health": their exaggerated emphasis on the ideal of health may cause them to falter with respect to some ordinary moral requirements, but society gains far more than it loses from allowing this extreme commitment in its healers.

\section{BLOCKERS/SPOILERS}

Whether a professional ethic is developed and nurtured is not only a question of supply and demand. It also depends on the existence and power of 'spoilers', who stand to benefit from the non-existence of the professional ethic and its ensuing obligations and enforcement regimes. We can think of spoilers as saying, "We resist the imposition of this norm because..."

One important spoiler group comprises service-providers (and prospective service-providers) who benefit from weak barriers to market entry. These include would-be service-providers who do not possess the educational credentials required for professional accreditation (Frumento \& Korenman, 2013). Some service-providers might also benefit from avoiding high compliance costs, especially if their preferred market strategies involve practices that clash with the demands of a professional ethic. Such spoilers can have much to lose from the imposition of new professional standards - such standards 
may see them forced out of a potentially lucrative market, or forced to act in ways that threaten their profit-margins within that market.

Along with this group of service-providers, we might also note their prospective clientele (though these rarely have any political voice). It may seem strange to think of clients benefiting from the removal of professional status, but the standards and processes required by the professional ethic and its regulatory machinery can carry significant costs and require significant personal investments (such as in timeconsuming education). These factors often conspire to inflate the cost of the service, and impact upon its easy and timely availability. To budget-conscious consumers, or in cases with lower stakes, professional standards may present as a barrier to their preferred way of engaging the service. They would prefer to try their luck in an unregulated market rather than to bear the inflated service-costs of a professional.

Another important spoiler comes in the form of product creators that stand to increase sales through unregulated, unprofessional sales strategies and marketing. Creators of financial products and pharmaceutical companies - consider 'natural' therapies - can fall into this bracket. Many pharmaceutical companies, for example, would prefer to advertise (e.g., as occurs in the United States and New Zealand) and even market directly to consumers, rather than having their products sitting behind the mediating layer of professional medical providers. For this reason, such providers can possess strong reasons for marshalling resistance to, or otherwise corrupting, professional ethical norms.

\section{CONCLUSION}

By understanding the demander-groups, the supply-factors, and the spoilers at work, we can come to an improved understanding of why professional ethics emerge in any given case. We can also begin to see why we require these norms of the classic professions (such as medicine, law, engineering), while we do not require them of ordinary business actors. Simply, the presence of both demanders and supplyfactors differs in each case. Businesses do not normally deal with clientele who suffer sweeping and multifaceted vulnerabilities, ensuring these businesses face less demand for stronger and more standardized ethical conduct. As well, without a specialized field of knowledge requiring lengthy study, fewer natural barriers stand in the way of market entry. This renders the formation of a closely knit and recognizable community of peers less likely, in turn removing many of the institutional supports for the creation of supply-factors. As well, a specific service, with standards distinct from mere monetary outcomes, naturally acquires its own notions of excellence. Business management, on the other hand, involves shifting between many different activities, making attributions of excellence murkier.

The above analysis also provides resources for reformers aiming to improve compliance with professional norms. Reformers can consider which groups of demanders to empower, and what levers 
of power those demanders might be able to wield that can impact upon compliance. Equally, reformers can look to the supply-side and assess what resources and institutions could be strengthened to enhance the norms' internal allure to its duty-bearers. To be sure, the foregoing analysis implies that aspiring reformers cannot simply 'build' an ethic from scratch; ethical drivers rely either on intrinsic human sensibilities (such as for common morality), entrenched cultural values (such as for true glory and the bargain for social status) or virtues constructed over lengthy periods and through long traditions of practice (role-identities, excellence and constructed virtues). But the reformer can, nevertheless, consider what cultural or institutional requisites and facilitators exist - or could exist - within the profession that could provide a fertile ground for the future growth of such ethics.

In such ways as these, the foregoing analysis aims to aid not only our understanding of professional ethics, but our practical reform efforts. ${ }^{13}$

\section{REFERENCES}

0'Brien, J., \& Dixon, O. (2013). The Common Link in Failures and Scandals at the World's Leading Banks. Seattle University Law Review, 36, 941-972.

Aristotle. (350BC/2002). Nicomachean ethics (J. Sachs, Trans.). Newbury, MA: Focus Publishing/R. Pullins.

Attas, D. (1999). What's wrong with "Deceptive" Advertising? Journal of Business Ethics, 21(1), 4959.

Beauchamp, T. L., \& Childress, J. (2009). Principles of biomedical ethics (6th ed.). New York: Oxford University Press.

Breakey, H. (2012). Intellectual Liberty: Natural Rights and Intellectual Property. Surrey: Ashgate.

Breakey, H. (2014). Wired to Fail: Virtue and dysfunction in Baltimore's narrative. Research in Ethical Issues in Organizations, 11, 51-80.

Breakey, H. (2016 Forthcoming). Compromise Despite Conviction: Curbing Integrity's Moral Dangers. Journal of Value Inquiry, 1-16. doi: DOI 10.1007/s10790-016-9541-1

Curtis, G. (2008). Greycourt White Paper No. 44: The Financial Crisis and the Collapse of Ethical Behavior: Greycourt.

Davis, M. (1988). Professionalism Means Putting Your Profession First. Georgetown Journal of Legal Ethics, 2(34), 340-357.

Davis, M. (1991). Thinking Like an Engineer: The Place of a Code of Ethics in the Practice of a Profession. Philosophy \& Public Affairs, 20(2), 150-167. 
Dolovich, S. (2010). Ethical Lawyering and the Possibility of Integrity. In T. Dare \& W. B. Wendel (Eds.), Professional Ethics and Personal Integrity (pp. 125-185). Newcastle upon Tyne: Cambridge Scholars Publishing.

Freedman, B. (1978). A Meta-Ethics for Professional Morality. Ethics, 89(1), 1-19.

Frumento, A. J., \& Korenman, S. (2013). Professionalism and Investment Advisers. Journal of Investment Compliance, 14(1), 32-41.

Gioia, D. A. (1992). Pinto Fires and Personal Ethics: A Script Analysis of Missed Opportunities. Journal of Business Ethics, 11(5/6), 379-389.

Graham, J. L. (2001). Does integrity require moral goodness? Ratio, XIV, 234-251.

Hall, R. T. (1982). Emile Durkheim on Business and Professional Ethics Business \& Professional Ethics Journal, 2(1), 51-60.

Hardin, G. (1968). The Tragedy of the Commons. Science, 162, 1243-1248.

Heath, J. (2008). Business Ethics and Moral Motivation: A Criminological Perspective. Journal of Business Ethics, 83, 595-614.

Hume, D. (1739/1969). A Treatise of Human Nature. Baltimore, Md.: Penguin Books.

Hursthouse, R. (1999). On Virtue Ethics. New York: Oxford University Press.

Igneski, V. (2006). Perfect and Imperfect Duties to Aid. Social Theory and Practice, 32(3), 439-466.

Iseda, T. (2008). How Should We Foster the Professional Integrity of Engineers in Japan? A PrideBased Approach. Science and Engineering Ethics, 14, 165-176.

Kelly, B. (1998). Preserving Moral Integrity: A Follow-up Study with New Graduate Nurses. Journal of Advanced Nursing, 28(5), 1134-1145.

Luban, D. (2003). Integrity: Its Causes and Cures. Fordham Law Review, 72(2), 279-310.

Macaulay, M., \& Arjoon, S. (2013). An Aristotelian-Thomistic Approach to Professional Ethics. Journal of Markets \& Morality, 16(2), 507-524.

Macdonald, K. M. (1999). The Sociology of the Professions. London: Sage.

MacIntyre, A. (1981). After virtue: a study in moral theory. London: Duckworth.

MacIntyre, A., \& Dunne, J. (2002). Alasdair MacIntyre on Education: In dialogue with Joseph Dunne. Journal of Philosophy of Education, 36(1), 1-19.

McGraw, D. K. (2004). A Social Contract Theory Critique of Professional Codes of Ethics. Information, Communication and Ethics in Society, 2, 235-243.

Montesquieu. (1748/1989). The Spirit of the Laws. New York: Cambridge University Press. 
Newton, L. (1982). The Origin of Professionalism: Sociological Conclusions and Ethical Implications Business \& Professional Ethics Journal, 1(4), 33-43.

Rhodes, R. (2001). Understanding the Trusted Doctor and Constructing a Theory of Bioethics. Theoretical Medicine, 22, 493-504.

Rhodes, R., \& Smith, L. G. (2006). Molding Professional Character. In N. Kenny \& W. Shelton (Eds.), Lost Virtue: Emerald.

Sampford, C. (1994). Law, Ethics and Institutional Reform: Finding Philosophy, Displacing Ideology. Griffith Law Review, 1(1), 1-38.

Sanders, D., \& Roberts, A. (2015). White Paper: Professionalisation of Financial Services. Parramatta: Professional Standards Councils (PSC).

Smith, A. (2006). The Theory of Moral Sentiments (6th ed.). Mineola, New York: Dover Publications.

Tapper, A., \& Millett, S. (2014). Is Professional Ethics Grounded in General Ethical Principles? Theoretical and Applied Ethics, 3(1), 61-80.

Tuch, A. F. (2014). The Self-Regulation of Investment Bankers. George washington law review, 83, $101-175$.

Veatch, R. M. (1979). Professional Medical Ethics: The Grounding of Its Principles. The Journal of Medicine and Philosophy, 4, 1-19.

Williams, B. (2002). Truth \& truthfulness: an essay in genealogy. Princeton, N.J.: Princeton University Press.

\footnotetext{
${ }^{1}$ This definition constitutes a mix of how social scientists and philosophers typically view norms. Philosophers tend to stress that norm compliance only counts when the norm is obeyed for the right reasons - but for our purposes here I count any motive that drives respect for the norm as such, rather than just the philosophically 'right' reason (which of course would be much debated by different schools of thought). Social scientists (such as from international relations studies) will recognize a norm only when they see widespread compliance, and expectations of compliance, regardless of whether the motive for obeying the norm involved respect for the norm as such. My definition thus straddles the two approaches.

${ }^{2}$ These are well-known features: e.g., Tuch, 2014, p. 111.

${ }^{3}$ See Rhodes, 2001. Naturally, further trust often must still be built, over time and individually with each client. Even here however, the larger collective ethic helps; it helps frame client expectations and fit a model of 'professionalism' that each individual can employ to demonstrate their trustworthiness.

${ }^{4}$ Some sociologists see this inter-profession competition as a key driver in professionalization; see Macdonald, 1999, pp. 15, 33.

${ }^{5}$ Though note that there can in some cases be rival service-providers able to be drawn in from cognate areas. See n. 4 above.

${ }^{6}$ One special case of this inelasticity arises when the service, through its very nature, can only be performed with state authority. In such cases, market competition cannot improve standards of service. This unavoidable-state-monopoly, applying to politicians, public servants, judges, police and armed
} 
forces, need not create recognizably professional ethics (though state prosecutors are professional lawyers) - but it does drive the formation of other ethical codes, and attendant enforcement measures.

${ }^{7}$ Deen Sanders employs an analogous supply-demand line of thought in his formula for determining the need for regulation or professionalization, outlined in Sanders \& Roberts, 2015. On the formula's numerator, Sanders places the vulnerabilities created by complexity, necessity for engagement and the risk of using non-experts, with trust in existing sources of expertise placed in the denominator.

${ }^{8}$ The community takes an increased role as demander in contemporary democratic contexts (sometimes referred to as Mode 2 societies) where the collective searches and creates knowledge, and then articulates informed political demands. See Sanders \& Roberts, 2015, p. 19.

${ }^{9}$ See http://www.psc.gov.au/

${ }^{10}$ Even if the reader thinks common morality fully explains all professional moral obligations and their binding status, this paper's argument can still be seen as a study in how to use various ancillary motivational devices to augment compliance with (what the reader in question will see as) ordinary moral duties as applied to special situations.

${ }^{11}$ Sociologists refer to this community-profession bargain as the 'function/functionalist' theory of professionalism (Newton, 1982), and its contractual mechanism as a 'regulative bargain' between profession and state (Macdonald, 1999, p. 11).

${ }^{12}$ Montesquieu once made this point with respect to the monarch's use of honor as the principle to motivate nobles' compliance with their obligations of state. The monarch may at times wish to demand actions that deviate from honor's requirements, but he cannot do so without undermining the very ethos that holds his country together: "Honor has its laws and rules and is incapable of yielding, as it depends on its own caprice and not on that of another" (Montesquieu, 1748/1989, p. 27). In other words, the supply-factor proves incapable of answering the demander's desires. For discussion of Montesquieu's point in a professional ethics context, see Breakey, 2014, p. 76.

${ }^{13}$ This paper benefited from helpful comments from Deen Sanders and Charles Sampford, as well as from participants at the $22^{\text {nd }}$ Annual Conference of the Australian Association of Professional and Applied Ethics, July 9-12, 2015, and from an anonymous reviewer for Research in Ethical Issues in Organizations. 